\title{
From Discussion Forums to eMeetings: Integrating High Touch Strategies to Increase Student Engagement, Academic Performance, and Retention in Large Online Courses
}

\author{
Glenda H. E. Gay \\ The University of the West Indies at Cave Hill \\ Kristen Betts \\ Drexel University
}

\begin{abstract}
Student engagement and group work are critical to developing competencies, deeper learning, and attributes that align with 21 st-century skills. In an increasingly competitive and dynamic workforce, the ability for employees to engage in collaborative workgroups is essential. A new capstone group-work assignment using Online Human Touch (OHT) strategies was integrated into an Information Systems course at a regional university in the Caribbean. The course typically enrolls $250-300+$ students per semester with one instructor. The assignment simulated a real-world business 'eMeeting' to proactively increase student engagement and retention. This action research study collected quantitative and qualitative data three years prior to and three years after the integration of the new 'eMeeting' group-work assignment. Quantitative data showed improved academic performance, higher scores on the standardized final exam, and decreases in attrition while qualitative data showed significant increases in student engagement. Integrating the 'eMeeting' assignment into the large online course provided students with the opportunity to apply the knowledge, skills, and experience gained throughout the semester. It also enhanced key soft skills sought by employers including problem-solving, ability to work in teams, communication, leadership, and time management.
\end{abstract}

Keywords: large courses, online instruction, online learning, distance learning, teacher presence, student engagement, attrition, retention, Online Human Touch, high touch strategies, group work, 21st-century skills

Gay, G.H.E. \& Betts, K. (2020). From discussion forums to eMeetings: Integrating high touch strategies to increase student engagement, academic performance, and retention in large online courses. Online Learning, 24(1), 92-117. https://doi.org/10.24059/olj.v24i1.1984 
From Discussion Forums to eMeetings: Integrating High Touch Strategies to Increase Student Engagement, Academic Performance, and Retention in Large Online Courses

\section{From Discussion Forums to eMeetings: Integrating High Touch Strategies to Increase Student Engagement, Academic Performance, and Retention in Large Online Courses}

Online enrollments worldwide have increased exponentially since the turn of the new millennium. In the United States, the proportion of higher education students enrolled in at least one online course increased to 33.1 percent in Fall 2017 from 31.1 percent in 2016. Concurrently, students enrolled exclusively online grew to 15.4 percent while students enrolled in a mix of online and in-person courses grew to 17.6 percent (Lederman, 2018). While cumulative online enrollment growth worldwide is more elusive to quantify, the global market for e-learning was estimated at \$90 billion in 2002 (Yong, 2003 cited in Chawla \& Joshi, 2012), \$166.5 billion in 2016 (Yu \& Hu, 2016), to a projected $\$ 275$ billion by 2022 (Reuters, 2017). It is evident through global market growth and increasing enrollments that online learning is now a cornerstone in education worldwide.

As institutions of higher education (IHE) continue to expand online offerings, academic quality and the student experience must be central to course design and instruction. This is of particular importance for large online courses in which enrollments may reach 150 students per course with one instructor. Very large online courses, which enroll 150 or more students per course, are often managed by one instructor with one or more teaching assistants (Elison-Bowers, Sand, Barlow, \& Wing, 2011). Therefore, instructing up to 150 students in a large online course or 150+ students in a very large online course is different than teaching the same online course with 20-60 students with one instructor or teaching the same course in a traditional on-campus classroom (Elison-Bowers, Sand, Barlow, \& Wing, 2011; Berry, 2009).

One of the primary challenges of students enrolled in online courses is their feelings of isolation, lack of community, and experiences of limited engagement with the instructor (Boton \& Gregory, 2015; Mokoena, 2013). These factors can result in higher attrition rates than traditional courses (Thomas, Herbert, \& Teras, 2014). For courses with enrollments of 150+, students may be at an even greater risk of attrition if these factors are not considered as part of course design or addressed through high touch instructional strategies.

The University of the West Indies (The UWI), a regional university in the Caribbean, was established in 1948 on the island of Jamaica with 33 students. The UWI now enrolls over 45,000 undergraduate students and approximately 9,000 graduate students across three physical campuses and an online campus. Of these 54,000 students, over 20,000 are enrolled through the online campus (The University of the West Indies, 2016). As part of the three-year undergraduate management degree, the Information Systems course is offered online every semester to second year students with typical enrollments of 250-350+ students per course per semester. Each Information Systems course has one instructor and four to five tutors who support student-toinstructor and student-to-student engagement. While instructors teaching the Information Systems course may not be concerned with students finding an open seat in a crowded large lecture hall, they are concerned with how to actively engage each of the 250-350+ students while taking the course that semester. 
From Discussion Forums to eMeetings: Integrating High Touch Strategies to Increase Student Engagement, Academic Performance, and Retention in Large Online Courses

\section{Review of Literature}

\section{Online Instruction with Large Courses}

Online education provides increased opportunities for students to enroll in many programs. Like on-campus programs, some online courses have increased student enrollments that mirror large lecture classrooms and may include 150 or more students. According to Berry (2009), "Teaching an online class session that has over 150 students enrolled is substantially different from teaching a face-to-face class on campus or an online class with 25-35 students" (para. 1). A key concern with large courses is that students may become disengaged or feel alienated which can "erode students' sense of responsibility and lead to behaviors that both reflect and promote lack of engagement" (Wilsman, n.d., para. 1).

As online education continues to grow worldwide, there is increasing literature on how to engage students in online courses. Strategies include keeping work relevant (Toney, 2017), providing opportunities for learner interaction (Briggs, 2015), and providing effective and timely feedback (Briggs, 2015; Toney, 2017). Creating opportunities for meaningful discussion and collaboration in a large online course is one of the biggest challenges of online instruction (Trammell \& LaForge, 2017). Therefore, implementing teaching techniques becomes an important factor in course design and successful management of large online courses.

\section{Group Work, Communication, and 21st-Century Skills}

Collaboration through group work (i.e., team work) is critical to developing competencies and attributes that align with 21st-century skills and deeper learning. According to the organization P21 Partnership for 21st-Century Skills, collaboration is the "ability to work effectively and respectfully with diverse teams" (Framework for 21st century learning, n.d.). In reviewing deeper learning competencies, collaboration occurs when "students learn to work in teams to achieve shared goals" (Bitter \& Loney, 2015, p. 3). Collaboration also supports the development of communication skills as students work together to collectively solve problems as a group.

Group work is an important attribute that prospective employers rate highly when employing graduates (Loughry, Ohland, \& Woehr, 2014). This is evident in annual national studies and media publications which identify skills that employers are seeking. According to the 2018 Job Outlook Report, the National Association of Colleges and Employers (NACE) reported that the top three attributes an employer seeks on a candidate's resume included: (a) problem-solving skills, (b) ability to work in teams, and (c) communication (para. 7). Business Insider in 2018 spotlighted what LinkedIn identified as the four most important soft skills employers are seeking, which included: (a) leadership, (b) communication, (c) collaboration, and (d) time management (Leighton, 2018). Recognizing that employers are seeking these critical soft skills, it is important that they are integrated into course design and instruction to support course and program outcomes.

As corporations become increasingly diverse, the ability to collaborate is critical whether employees are working onsite or virtually. Employees are expected to be able to communicate through email, discussion forums, and video conferencing. This study adapted the threads of a discussion forum to represent the phases of an online meeting conducted in the corporate sector. For the purpose of this study this capstone group assignment that simulated a business meeting is referred to as an eMeeting. 
From Discussion Forums to eMeetings: Integrating High Touch Strategies to Increase Student Engagement, Academic Performance, and Retention in Large Online Courses

\section{Online Human Touch}

The Online Human Touch (OHT) conceptual framework builds upon five areas of research that support student engagement, retention, and completion. The five areas include:

- Student Engagement (Astin, 1984; Chickering \& Gamson, 1987; Tinto, 1993)

- Personalized Communication (Faharani, 2003; Mehrabian, 1971)

- Community Development (Palloff \& Pratt, 1999; Stanford-Bowers, 2008)

- Work-Integrated Learning (Milne, 2005), and

- Data Driven Decision-Making (Cranton \& Legge, 1978).

Each of these areas, when integrated into program development, course design, and instruction, support student engagement through high touch strategies during the student lifecycle.

Student engagement. High touch student engagement strategies connect students to the instructor and other students through course orientation sessions, announcements, discussion forums, synchronous sessions, and group assignments. When students are fully engaged, focused, and present, they can experience flow, which is a state of optimal experience (Csikszentmihalyi, 1990; Spencer, 2017). Additionally, student engagement is an important factor in proactively addressing student retention and creating a lifelong bond with future alumni (Betts, 2008).

The literature has shown that students learn best when they have specific assessment guidelines, including a rubric (Rose \& Smith, 2007). Furthermore, students learn better and faster through multimedia presentations that supplement text-based coursework, thus allowing them to review content at their own pace (Buzzetto-More, 2015).

Personalized communication. High touch personalized communication strategies encourage regular and ongoing interaction with the instructor (e.g., faculty, adjunct faculty), and students. It involves being active in the discussion forums, such as using students' names when responding to posts; providing customized feedback on graded assignments; and having meetings with students or groups via Zoom or Skype regarding activities, assignments, or as needed. Feedback using multiple modalities also supports personalized communication through text, voice, and video feedback on assignments and group work.

A 2018 study by the National Association of Colleges and Employers (NACE) revealed that students may have a higher perception of their own communication and collaboration skills than that of actual employers. For example, a NACE report showed that when asked to rate their oral and written communication skills as well as their ability to work with others in teams, students overall rated themselves $79.4 \%$ for oral/written communication and $85.1 \%$ for working with others in teams (Bauer-Wolf, 2018). However, for these same skill sets, employers rated students at $41.6 \%$, and $77 \%$ respectively (Bauer-Wolf, 2018). Providing creative and personalized feedback can therefore be used to enhance students' written communication skills, while demonstrating to students that the instructor and tutors are interested in their contributions (Mokoena, 2013). Feedback by the instructor is also important since it could serve as a catalyst for students who have yet to join or engage in the discussion threads (Rose \& Smith, 2007).

Community development. High touch community development strategies involve creating activities that support student-to-instructor and student-to-student engagement. Community development can be fostered through discussion forums that actively engage students with topics relevant to weekly/module content, current/emerging issues, and upcoming assignments. Discussion forums can also incorporate group assignments in which students collaborate 
From Discussion Forums to eMeetings: Integrating High Touch Strategies to Increase Student Engagement, Academic Performance, and Retention in Large Online Courses

asynchronously or synchronously. "The starting point for learning occurs when knowledge is actuated by learners connecting to and participating in a learning community" (Goldie, 2016, p. 1065).

Collaboration skills are critical to today's workforce. According to Laux, Luse, and Mennecke (2016), "When students use a virtual community as a basis for learning, they are exposed to unfolding events similar to real life. This is different from a single exposure to a concept in one classroom session" (p. 289). However, there are some students who tend to participate in group discussions but give shallow or short responses instead of providing in-depth reflective responses that integrate their experiences with the material (Rose \& Smith, 2007; Mokoena, 2013). The Partnership for 21st Century Skills organization suggests that when collaborating, students should develop the ability to work effectively and respectfully in their group, exercise willingness in making necessary compromises to accomplish a common goal, assume shared responsibility for collaborative work, and value the individual contributions made by each team member (n.d., para. $1)$.

Work-integrated learning. High touch work-integrated learning strategies assist students in understanding the connection between activities and assignments and real-world issues. It aligns with various instructional strategies that support providing student choice while adhering to the same learning objectives and rubrics. For key assignments, this high touch strategy could include having students select a topic of their choice, within identified parameters, which supports interest, relevance, and significance for assignments that align with real-world contexts on current and emerging issues related to the course.

Experiential and work-integrated learning are important when students are able to make content applicable to their real-world experiences and they are involved in assignments in which they use research and creative thinking skills, develop ideas, or solve a problem (Bigatel, 2016). In postsecondary education, "experience-based education has become widely accepted as a method of instruction" (Kolb, 2014). Learning experiences that expose students to a professional culture and workplace practice are needed to support this transition from study to employment (Betts, 2008).

Data-driven decision-making. High touch data-driven decision-making strategies involve formative and summative assessment. Diverse learning assignments actively engage students in becoming reflective learners and practitioners. This can be achieved through personalized feedback with scaffolded assignments as well as peer evaluation and self-evaluation (Betts, 2008). More so, it can also engage faculty in modifying, refining, expanding or replacing activities or assignments based on summative feedback from course evaluations or program reviews (Betts, 2008).

Collectively, the five research areas within the OHT framework support high touch strategies for student success and the transfer of learning across real-world contexts. This action research study, therefore, examined how the integration of an eMeeting design affected student engagement in the course. The following research questions were addressed:

1. How did the integration of an eMeeting designed using OHT strategies impact student success (i.e., academic performance, student engagement, attrition) in a large online course? 
From Discussion Forums to eMeetings: Integrating High Touch Strategies to Increase Student Engagement, Academic Performance, and Retention in Large Online Courses

2. How did students perceive the eMeeting using OHT strategies in a required Information Systems online course?

\section{Course Structure 2011-2013}

The original course in 2011 had three individual assignments, which included (a) one orientation activity, (b) one database project, and (c) one essay assignment. There were also weekly discussion forums and a standardized final exam. The orientation activity involved getting familiar with the course and an introduction to databases. The database project included creating queries and reports while the essay assignment focused on responding to an information systems issue. Students were assigned to groups of approximately 20-30 with one tutor per group. Each tutor was responsible for their group's student orientation and for grading their students' submissions for the database project, essay assignment, and discussion forums. There was no capstone group work assignment in this course structure.

The assigned weekly discussion forums were designed to test fundamental concepts where students were required to read chapters from an online course manual and post responses to generic questions in the weekly discussion forum. Therefore, group work was incidental since students were placed in groups on registration and assigned a tutor. There were also limited guidelines on how to actively participate in the groups. According to the literature, a lack of guidance on how to effectively work as a group may cause a "sink-or-swim" approach (Vik, 2001). Moreover, research by Rose and Smith (2007) indicates that the stipulation for 'participation in group discussions' tends to be too vague in terms of what is required of students as well as the extent and level of participation. Having minimal guidance on what was generally permitted or expected in a group environment did not foster or optimize student interaction. Students therefore replied to the primary thread and to two other students in their group to meet the requirements, but the responses typically did not go beyond the initial prompt. The final exam was a proctored, standardized twohour written exam that followed The UWI's regulations for course completion.

\section{Course Structure 2014-2016 with the New eMeeting Design}

The original Information Systems coursework in 2011-2013 and the revised coursework in 2014-2016 shared the same learning outcomes, weekly objectives, assignments, readings, and discussion forums. The orientation activity and database project still involved becoming familiar with the course and introduction to databases. However, the essay assignment was revamped as a capstone group-work assignment. It was now a two-week asynchronous discussion forum that was introduced to the students as an eMeeting. Additionally, a restructured and enhanced standardized final exam now focused on a case study.

The eMeeting was designed to simulate a real-world online business meeting as well as proactively increase student engagement and retention. The discussion threads of an eMeeting were sequenced, starting from student introductions though various tasks to the group's final submission. The sequencing provided guidance as students progressed through the threads of the eMeeting. Additionally, the eMeeting design integrated the strategies from the OHT conceptual framework to support student engagement and retention. The OHT framework asserts that students are more likely to persist in an online program if they are engaged in and outside of their courses; the educational experience is personalized; and activities support transfer of learning across real-world contexts (Betts, 2008). 
While instructor presence and teaching were and are still important aspects of the course, the role of the tutor has shifted from primarily grading course assignments and providing feedback to guiding and engaging students with high touch strategies through the eMeeting. This new approach now provides students with extended opportunities to develop critical workforce skills, explore career interests, and build upon prior knowledge. Additionally, this new knowledge could allow them to gain exposure to 21st-century skills and align with The UWI's attributes in order to expand their network, increase their regional identity and global awareness, and identify innovative ways to transfer new knowledge and skills as socially, culturally, and environmentally responsible citizens.

\section{Methods}

Action research was selected for this study since this methodology is used in real-world contexts to solve problems and improve professional practice. Action research is typically conducted by practitioners to explore practical problems in which the research results in a desired change that is shared within an educational community (Norton, 2018; Efron, 2013). Parsons and Brown (2002) define action research as follows:

Action research is a form of investigation designed for use by teachers to attempt to solve problems and improve professional practices in their own classrooms. It involves systematic observations and data collection which can be then used by the practitionerresearcher in reflection, decision-making and the development of more effective classroom strategies (p. 55).

Action research typically includes between three to seven or more steps. However, for the purpose of this study, there were five steps (see Figure 1).

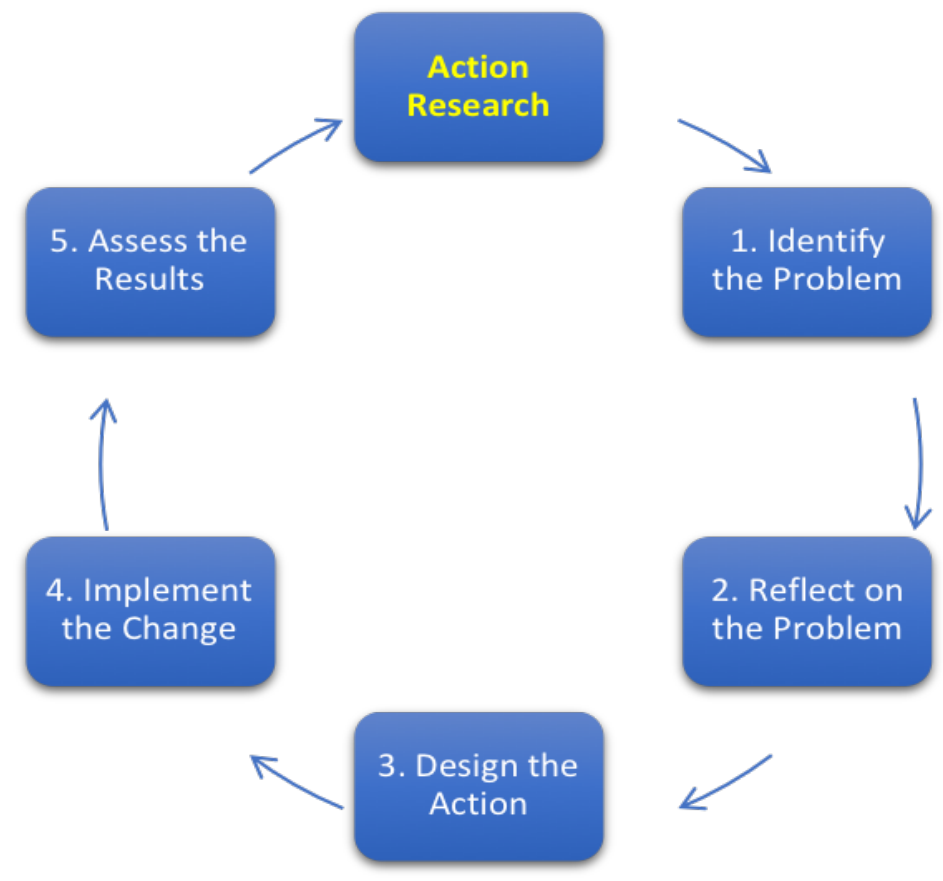

Figure 1. Action research steps for this study. 
From Discussion Forums to eMeetings: Integrating High Touch Strategies to Increase Student Engagement, Academic Performance, and Retention in Large Online Courses

Both quantitative and qualitative data were collected three years prior to and three years after the new 'eMeeting' assignment. Quantitative data, including exam scores and student attrition before and after the introduction of the OHT strategies, was summarized and evaluated for trends in attrition. Qualitative feedback was also collected from over 2,000 posts during the eMeeting.

\section{Context and Setting}

One of the core undergraduate management programs in Social Sciences at The UWI is Information Systems. Like many IHEs, required courses in management programs can have very large enrollments. The UWI's Information Systems course typically enrolls 250-350+ students per course per semester and is offered online every semester to second year students pursuing a threeyear undergraduate management degree. Each Information Systems course has one instructor and four to five tutors who support student-to-instructor and student-to-student engagement. Instructors therefore want to ensure that they are actively engaging the 250-350+ students enrolled in the course.

The Information Systems course model builds upon an instructor-tutor relationship. Students first register for the course that has one instructor. Within the course, students are then assigned to groups of approximately 20-30 with one tutor per group. The tutors are adjunct faculty, who are working professionals with content expertise. They are required to complete The UWI's online training courses on managing and facilitating online instruction. In their role as tutors, the adjunct faculty are actively involved in the discussion forums providing workforce-related perspectives. They are also responsible for grading their group's assignments and providing student feedback.

This method allows the instructor to focus on "managing the course" throughout the semester. This includes preparing and posting course materials and assignments, such as integrating supplemental materials related to current and emerging issues into the weekly course content and the discussion forums, preparing rubrics (mark schemes), leading synchronous sessions, and managing the student-tutor experience. The instructor also posts weekly reminders, course-related announcements, and any institutional-related announcements.

Interaction is paramount in this course. The instructor is also responsible for managing the instructor-tutor interaction, which includes required online meetings throughout the semester. The instructor first reviews the coursework for the upcoming semester and discusses any nuances regarding the new assignments with the tutors. Each tutor is required to complete the course assignments. This provides a unique collaborative opportunity for the instructor and tutors to discuss the assignments and make any needed modifications before they are approved for use. Although the tutors are responsible for grading assignments, the instructor "standardizes" the grading by randomly selecting samples from each group to ensure consistency of grading, and for quality control. The instructor also ensures that the tutors mark assignments and enter the marks within a two-week period. Students would then have the opportunity to reflect on the feedback prior to the next assignment submission. This approach, in many ways, fosters a student relationship with both the instructor and a professional within the field (the tutor).

\section{Sample}

Convenience sampling was used for This study and included 3,386 students who were enrolled in the Information Systems online course over a six-year period: 2,386 between 20112013, and 1,500 students between 2014-2016. All students were enrolled in the second year of 
From Discussion Forums to eMeetings: Integrating High Touch Strategies to Increase Student Engagement, Academic Performance, and Retention in Large Online Courses

their undergraduate program. Table 1 provides an overview of student enrollments across the same course that was offered between 2011-2016.

Table 1

Student Enrollment

\begin{tabular}{cc}
\hline Year & Student Enrollment \\
\hline 2011 & 801 \\
2012 & 834 \\
2013 & 751 \\
$2014^{\mathrm{a}}$ & 547 \\
2015 & 484 \\
2016 & 469 \\
\hline
\end{tabular}

Note. ${ }^{a}$ refers to the year of integration of the eMeeting design using OHT strategies.

\section{The eMeeting Design with OHT Strategies}

Students were sorted alphabetically by their first name and then assigned to sub-groups of five where they could only see their own small group's activity in the eMeeting. Five sequenced threads were created using "MoodleForums," which supports multiple sub-forums. This tool was used to monitor student interaction and ensure clarity about participation (see Figure 2).

These five threads played an important role in guiding students through the stages of their eMeeting with instructions on how to participate at each stage. For a two-week period, students had access to their eMeeting. Each thread replicated the instructions for the specific task along with the corresponding rubric and grades (mark allocations). The left half of Figure 2 illustrates the outline of the five threads of the eMeeting. The right half of Figure 2 illustrates a screenshot of the contents of thread one, with the assignment document (at top) and an accompanying 10minute video created by the instructor (at bottom).

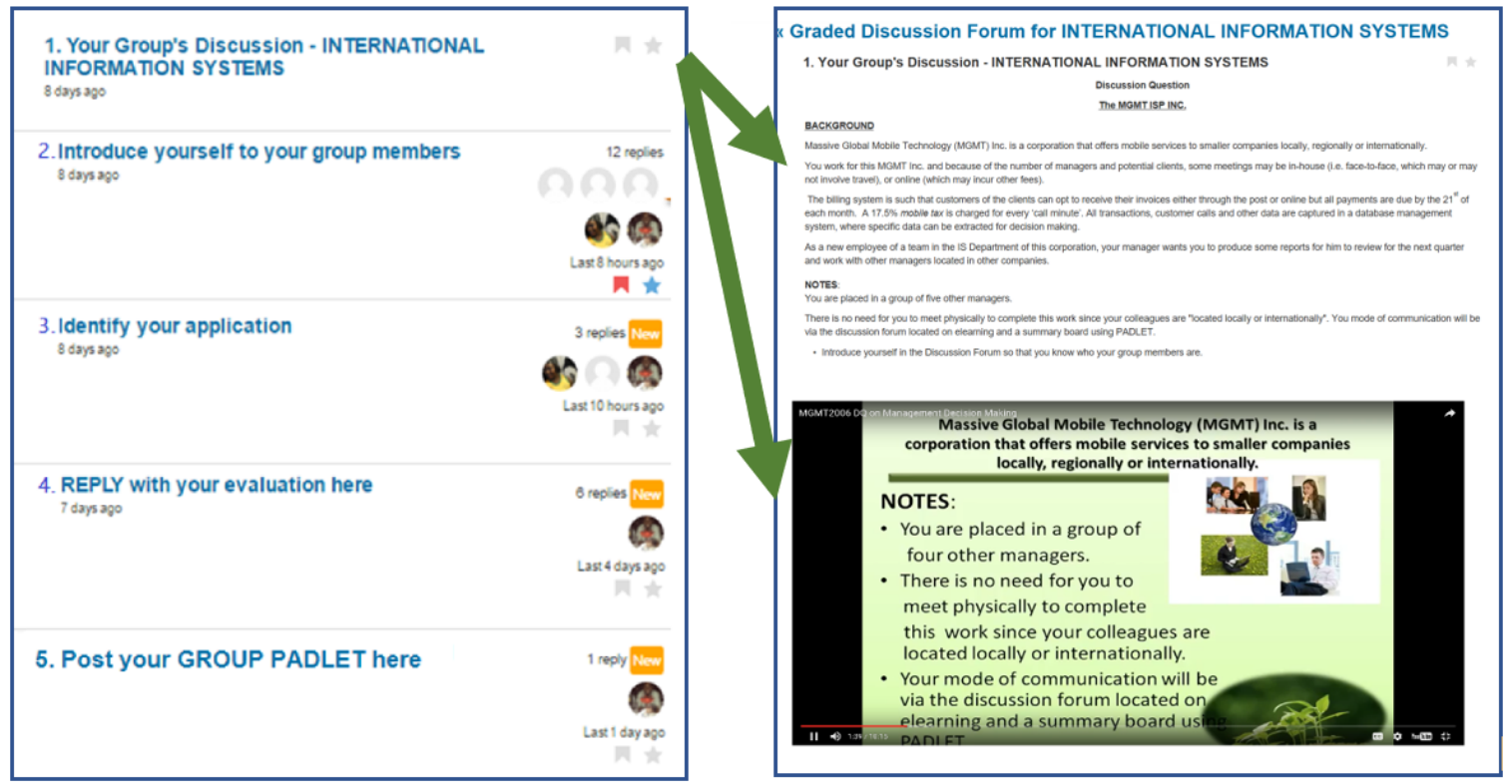

Figure 2. First thread of an eMeeting (upper left), comprising the course assignment document (upper right) and an accompanying instructor-led video (lower right). 
From Discussion Forums to eMeetings: Integrating High Touch Strategies to Increase Student Engagement, Academic Performance, and Retention in Large Online Courses

Table 2 provides an overview of the content for the eMeeting threads with associated high touch strategies.

Table 2

Overview of eMeeting Threads with High Touch Strategies

eMeeting Assignment materials: Each group's assignment instructions are posted in this thread Thread 1 along with an instructor-led video explaining the requirements.

High Touch Strategy: Student Engagement (Instructor-Led Videos). A video describing the approach and purpose of the eMeeting was developed to ensure that all requirements were clear. The video also integrated metacognitive approaches to learning by relating the direct connection between their eMeeting and business communication skills that can be readily transferred to the workforce. Additionally, the video referenced the assignment document that detailed the course work rubric, so that students were aware of how they would be assessed. Students were also advised that they would not be graded for partial, vague or general responses.

eMeeting

Thread 2

Introductions: Each member is expected to greet each other and provide specific information identified in the instructions.

High touch strategy: Personalized communication (self-introductions). This strategy required students to introduce themselves in preparation for interacting in an online business setting as opposed to a social situation. The instructor video provided in Thread 1 included examples of how students should introduce themselves in an online environment, so that they were able to gain marks for creating their personalized introductions for the eMeeting. The list of students was also sorted by first name before allocating them to their five-member groups. This intentional sorting resulted in students sharing similar names or initials, which could be used as an icebreaker to start interaction and build camaraderie.

eMeeting

Thread 3

Topic Selection Group Activity: Students suggest and then agree on a common aspect from the case study that will be used throughout the e-meeting.

High touch strategy: Community development with agreement on application. To foster this virtual community, Thread 3 required members to suggest and agree on a common application theme or topic from the case study that would be used throughout the eMeeting. Group members were expected to share similar interests and thus create freeflowing interactions among all group members.

eMeeting

Thread 4

Role Play Group Activity: This main thread was used by students to engage their group members using key terminology, database queries, and reports from a prior assignment. They were expected to incorporate this information based on the case study from which they make real-world decisions. Students are encouraged to use information from their database project or provide links to Internet sources that supported their decision-making.

High touch strategy: Work-integrated learning across real-world contexts. The eMeeting provided students with an opportunity to meet online regularly and discuss elements of their group assignment. This is similar to scheduled meetings within an organization when working on a project. This strategy also supported instructional strategies used by tutors to encourage further interaction in some groups, while creating friendly competition amongst members in other groups. 
eMeeting Thread 5

Summary Notice Board Group Activity: Students were expected to access their group's private online notice board to post outcomes, decisions, or recommendations from their discussions, but the final product should reflect each group's collective summary. The completed summary board is then embedded in this discussion thread as evidence of the group final activity.

High touch strategy: Community development (student-student brainstorming). Students demonstrate their collaborative skills by working effectively and respectfully throughout the eMeeting threads. Then, as they demonstrate willingness to assist group members to accomplish required objectives, it demonstrates the alignment with Partnership for 21 st-Century Skills.

\section{Evidence of High Touch Strategies: Data-driven Decision-making}

Quantitative and qualitative data was collected prior to and after the integration of the new 'eMeeting' group-work assignment to determine the effect of the high touch strategies on student engagement. Quantitative data included examining course pass rate, course evaluations, and attrition. Qualitative data included instructor observations, student posts, and student feedback on the new capstone group-work assignment.

\section{Results}

This study provides summary quantitative data on academic performance and course satisfaction as well as qualitative student feedback. Examples of five high touch strategies that align with the OHT framework are provided in the following tables and figures. The screenshots of examples and associated strategies are illustrated using the January-April (Semester 2) 2016 cohort. Of the 469 students enrolled in the course with access to Moodle, up to 68 smaller groups were created using a "MoodleForum" format that supports multiple sub-forums. This also enabled the five tutors to each monitor and actively work with approximately 13 five-member groups.

\section{Student Engagement}

Data collected from this cohort showed an average of 5,536 student visits to the eMeeting threads and 2,502 posts by the eMeeting deadline. Each of the 13 groups was also provided with an instructor-led video relating to an eMeeting case study. These videos were viewed 1,037 times while students worked through the tasks (see Table 3).

Table 3

Summary of Interactions Among Students at End of Each eMeeting for Semester 2, 2016

\begin{tabular}{lccc}
\hline \multicolumn{1}{c}{ eMeeting Case Study } & $\begin{array}{c}\text { Number of } \\
\text { posts at } \\
\text { deadline }^{\mathrm{b}}\end{array}$ & $\begin{array}{c}\text { Video } \\
\text { views }\end{array}$ & $\begin{array}{c}\text { Average } \\
\text { group mark } \\
\text { out of 15 }\end{array}$ \\
\hline 1. Management Reporting & 498 & 263 & 14 \\
2. Management Decision Making & 771 & 190 & 14 \\
3. Mobile Data Security & 332 & 167 & 13 \\
4. Systems Development & 404 & 223 & 14 \\
5. International Information Systems & 497 & 194 & 14 \\
\hline
\end{tabular}

Note. ${ }^{\mathrm{b}}$ Excluding private and miscellaneous posts 
Most of the students systematically followed the sequenced discussion threads. Additionally, student engagement in a majority of the eMeetings went beyond the requirements posted with each thread. The applied high touch strategies, instructor observations and exemplars of student posts from each thread are discussed in the following sections. Students' names included in posts have been modified to ensure anonymity.

\section{eMeeting Thread 1: High Touch Student Engagement Strategy}

\section{Assignment Materials}

With instructor-led videos. The new eMeeting design for this thread resulted in fewer questions from the students asking for clarification on some aspect of the requirements. They were able to refer to the written instructions and the instructor-led video to assist each other during the eMeeting.

Instructor observation 1. Many students watched the video first before starting the tasks and referred to the video repeatedly to ensure that they understood the tasks and knew what was expected of them. This suggested that they made the effort to meet those expectations (Figure 3, top).

Instructor observation 2. The information provided in the video was useful in guiding students with the specific technology tools required, while keeping them on task as they brainstormed during the group activity (Figure 3 bottom).

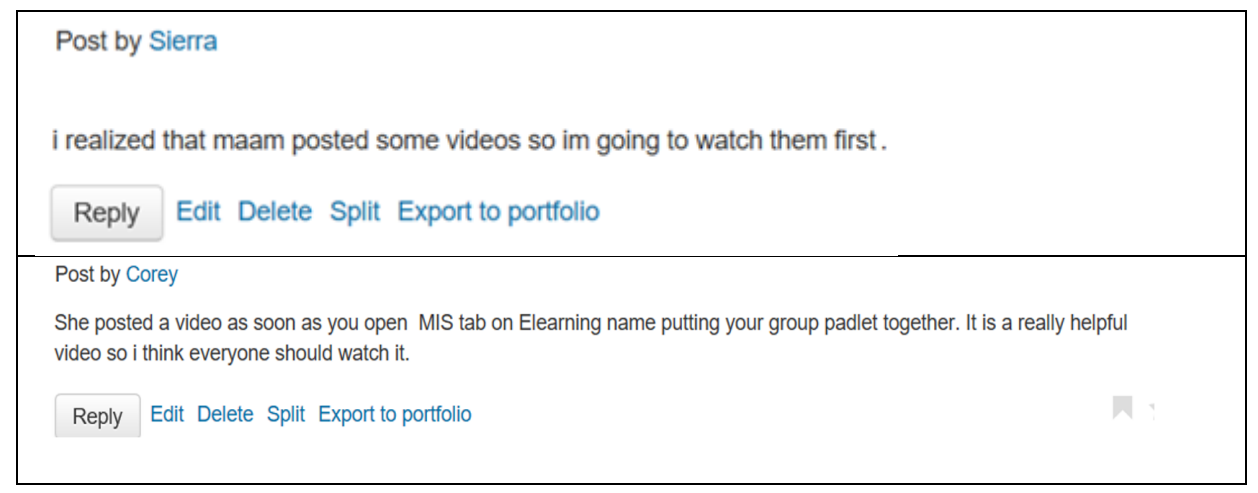

Figure 3. Students referring to the video in Thread 1.

\section{eMeeting Thread 2: High touch Student Engagement Strategy}

eMeeting with self-introductions. Students were not usually required to formally introduce themselves in discussion forums. However, it was a requirement for this eMeeting. For this thread, a few students posted a minimum response while others were professional, not only posting the correct information but reaching out to welcome their groupmates. Tutors also used this new self-introduction opportunity to guide students by posting private messages to those who did not meet the requirements for their introductory post.

Instructor observation 1. Some students used salutations in their greeting, such as "Hello, my name is...", which was an accepted and more formal style of communication. However, a few students greeted their colleagues using casual terms such as "Hey", or "Hi guys" which is often associated with informal social media types of greetings. (see Figure 4). 
From Discussion Forums to eMeetings: Integrating High Touch Strategies to Increase Student Engagement, Academic Performance, and Retention in Large Online Courses

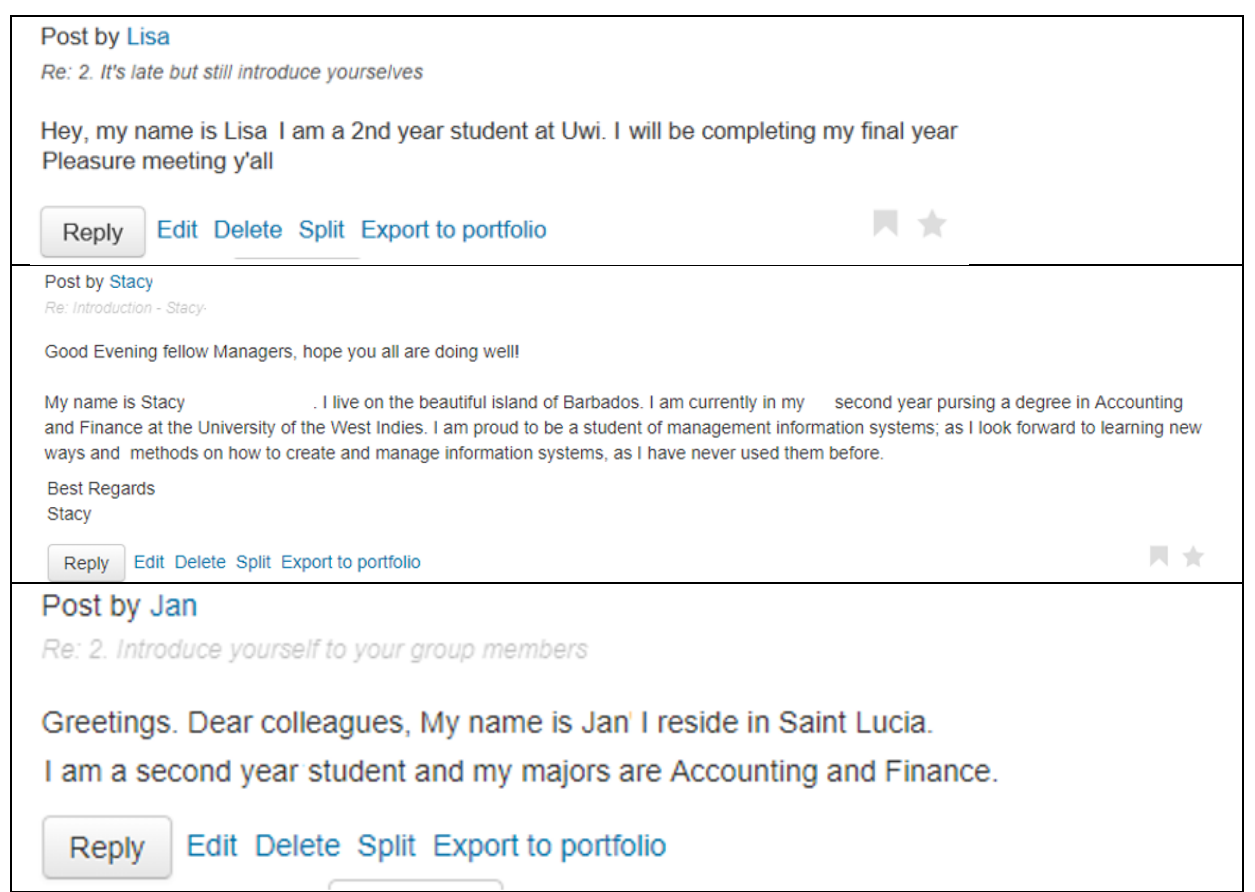

Figure 4. Examples of unsuitable (top example) and appropriate introductory posts (Bottom two examples).

Instructor observation 2. Several students reposted their corrected self-introductions (see Figure 5). The eMeeting also fostered a sense of community among members. For example, Figure 6 shows a sample of personalized communication from a student who reached out to a group member to direct her to the correct discussion thread.

Post by Nadia
Hey everyone! My name is Nadia, and I am from Montserrat. Can't wait to start working together!
Reply Edit Delete Split Export to portfolio
Rest by Nadia
Hello again! I did not see the minimum requirements, so please allow me to adjust my introduction. My name is Nadia, and I am a a Firch 2016, 12:06 AM Year
student at the Cave Hill campus pursuing a BSc. Accounting and Finance. I am 19 years old and I come from Montserrat. Can't wait to meet the
rest of you.

Figure 5. Example of reposted self-introduction. 
From Discussion Forums to eMeetings: Integrating High Touch Strategies to Increase Student Engagement, Academic Performance, and Retention in Large Online Courses

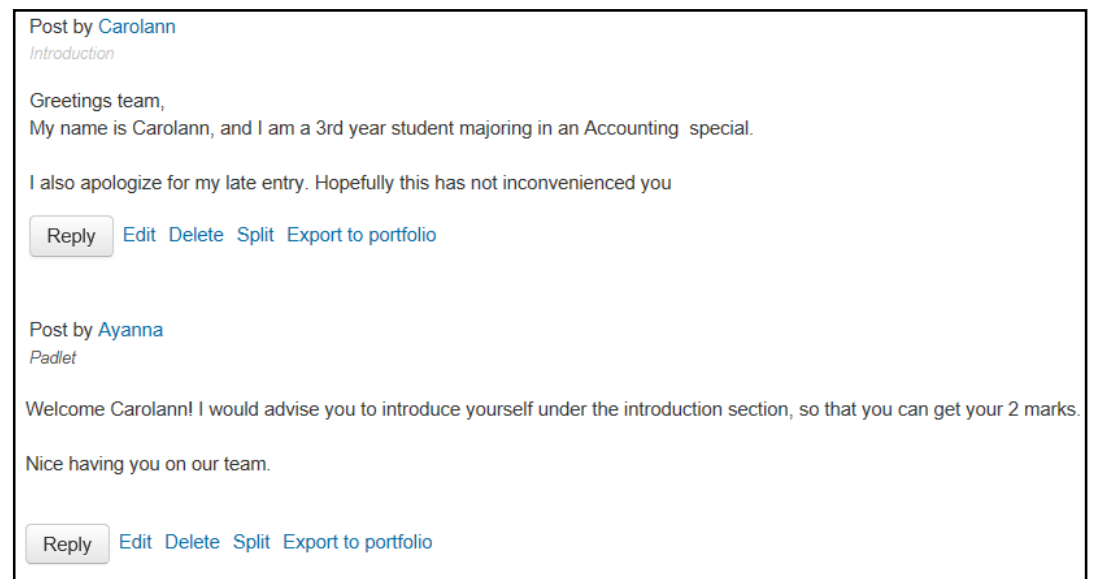

Figure 6. Example of personalized communication among group members.

\section{eMeeting Thread 3: High Touch Community Development Strategy}

Group decision-making with agreement on application. The requirements in this thread provided the structure for the eMeeting. It involved consensus for the selection of the application, theme, or topic. This thread was therefore designed to engage students in discussions as they collaborated on various components of the assignment.

Instructor observation 1. In one of the eMeetings, group members were required to post a suitable online application and explain their choice. In Figure 7, students recommended familiar video conferencing applications, thus integrating their previous experiences with the application to the activity in this thread.

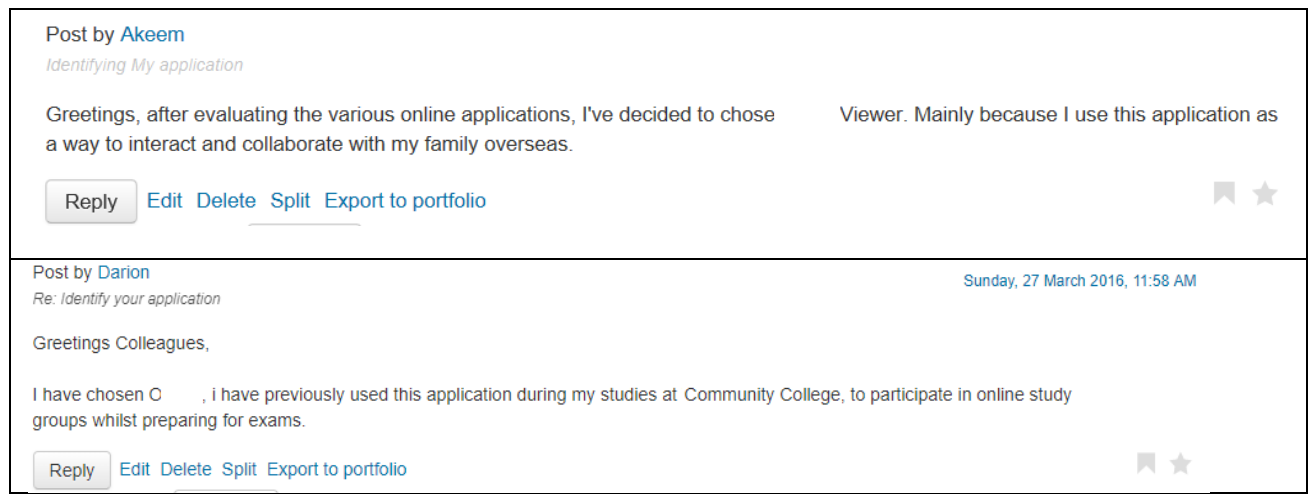

Figure 7. Students posting recommendations on a suitable application for video conferencing.

Instructor observation 2. In another eMeeting, students were required to choose a mobile phone and provide reasons why it would be appropriate for company employees to use that phone when travelling, given its cost and data plan. Some students posted their personal brand of mobile phone, stating generic reasons for their choice, while others compared various attributes of different phones showing that they conducted research and made informed decisions. The top post in Figure 8 shows examples of unsuitable posts. The bottom post in Figure 8 shows examples of well-researched posts. 


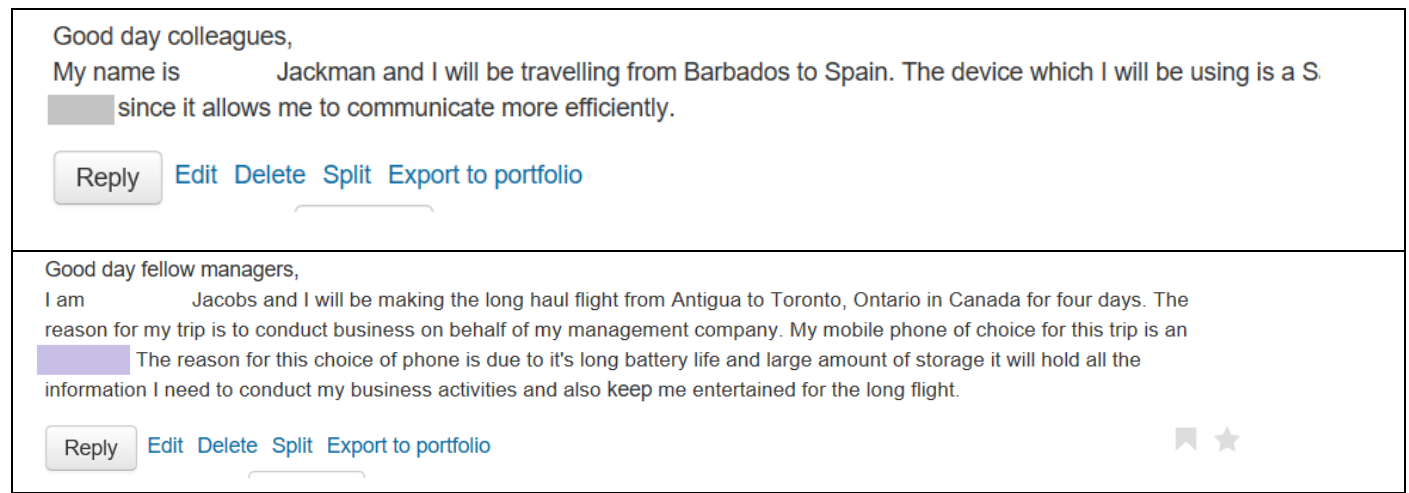

Figure 8. Students posting recommendations that were general (top) compared to wellresearched (bottom) regarding a choice of mobile phone when travelling.

\section{eMeeting Thread 4: High Touch Work-integrated Learning Strategy}

Role play group activity across real-world contexts. Students communicated and progressed through the threads of the eMeeting while receiving valuable feedback from their tutor and group members. Additionally, the instructor and tutors used creative ways to maintain the momentum for those who were engaged in the discussion. A key strategy used by one tutor was to engage a group's members as though they were working as managers and the tutor was a supervisor, thus changing the group dynamic and enhancing the quality of responses. Another strategy used by a tutor was a summary post at the conclusion of each eMeeting, which shared the progress of all groups, and provided them with a comparison of their progress among their peers.

Instructor observation 1. Figure 9 illustrated a strategy used by a tutor to engage students in an eMeeting. As the number of student comments increased, it became necessary to summarize the information in such a way, that it became a creative resource. Initially, some groups spent too much time in an earlier thread trying to agree on a common theme. Other groups were not as active, indicating that they were waiting for all members to make an initial post. One tutor not only praised groups for starting their eMeeting but used a memo to provide guidance and encouragement to those who had not posted or were not posting within the required deadlines. The tutor's memo was also written with a tone of urgency to align with the group's cybersecurity theme thus encouraging members to complete their tasks by the deadline to avoid a 'security breach' (Figure 9). 
From Discussion Forums to eMeetings: Integrating High Touch Strategies to Increase Student Engagement, Academic Performance, and Retention in Large Online Courses

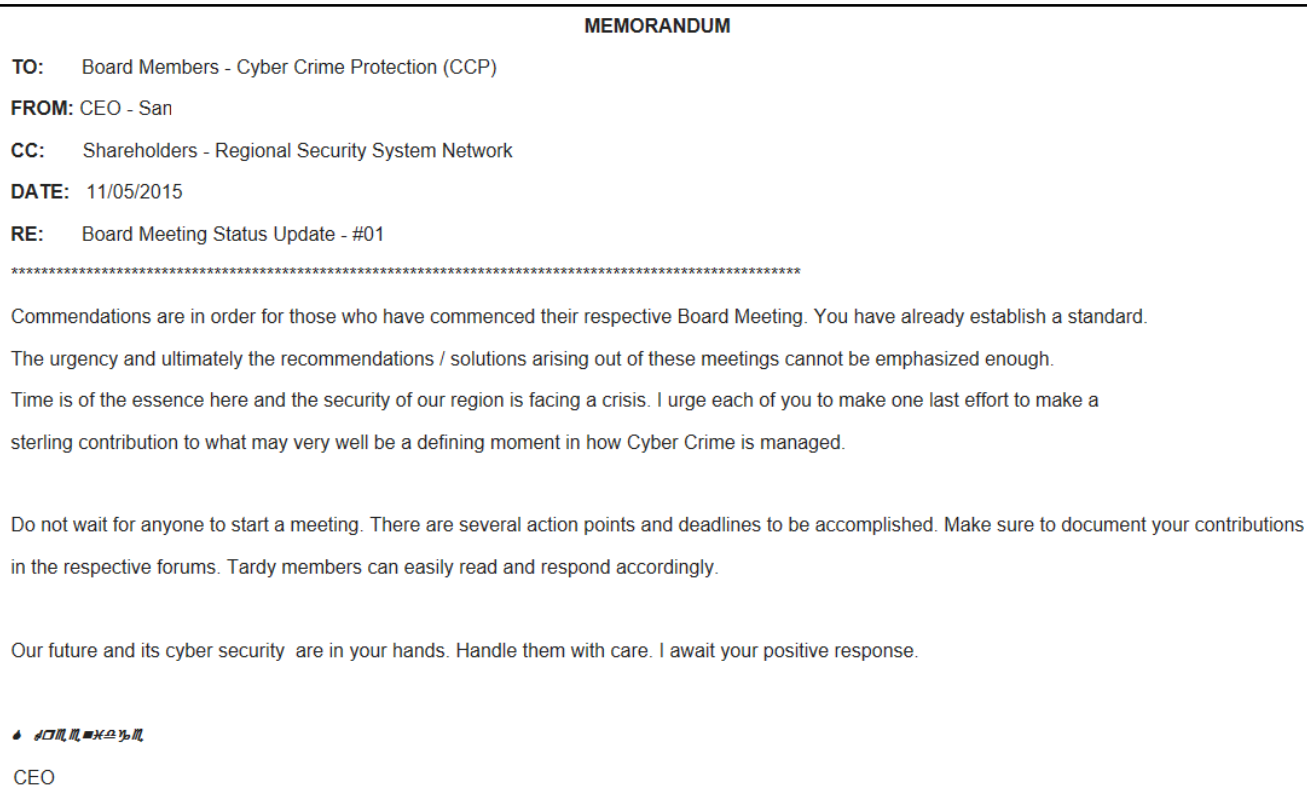

Figure 9. Tutor using a memo for role-play.

Instructor observation 2. Another tutor used a different strategy by posting a summary of the status of the groups' progression through the threads (Figure 10). This gave the students an overview of how well each group was performing without embarrassing or identifying anyone individually. In this summary post, groups B, D and E were progressing very well, and so the instructor used a competitive strategy to maintain their momentum. A teachable moment for groups $\mathrm{A}, \mathrm{C}$, and $\mathrm{F}$ from the memo was that the specific outcomes for the eMeeting were still required irrespective of the non-attendance of all group members.

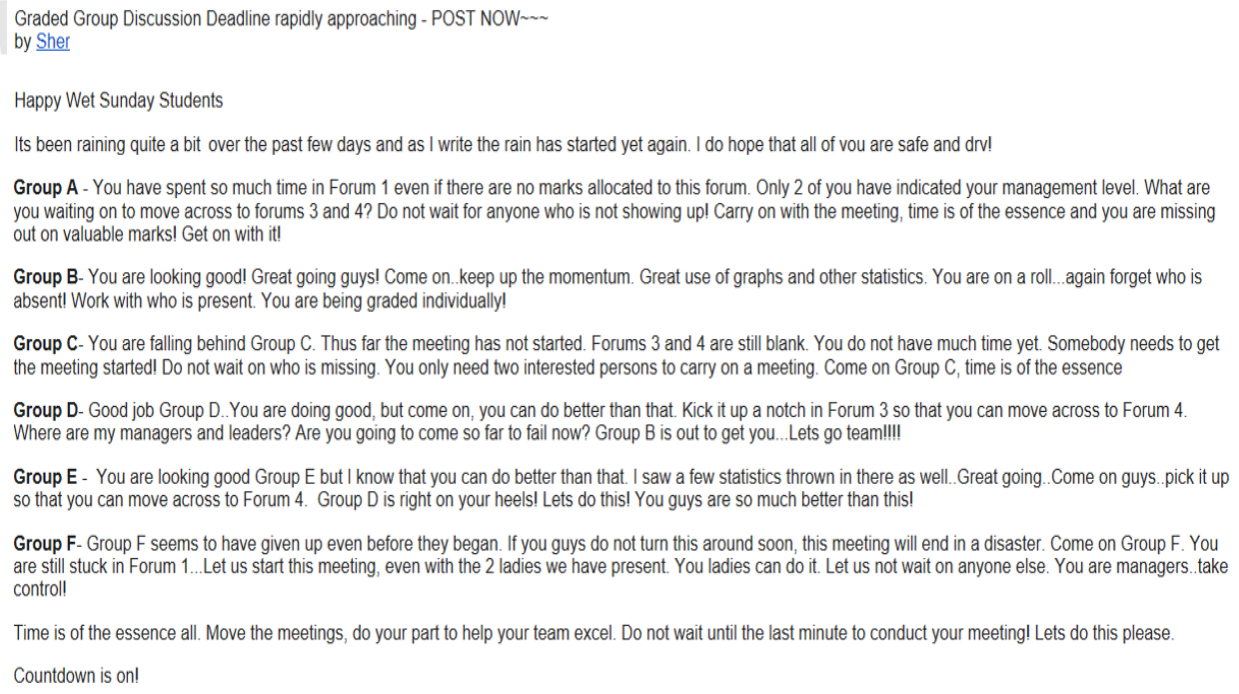

Figure 10. Tutor using group summaries for role-play. 
From Discussion Forums to eMeetings: Integrating High Touch Strategies to Increase Student Engagement, Academic Performance, and Retention in Large Online Courses

\section{eMeeting Thread 5: High Touch Community Development Strategy}

Group Submission with student-student brainstorming. In previous threads, students were expected to collaborate and agree on a common application, theme, or topic from the case study that would be used throughout the eMeetings, and then actively engage each other in a discussion. This last tasks of the eMeeting required students to assume shared responsibility for collaborative work. Students were expected to contribute ideas in order to create an online poster that reflects a cohesive summary of their group assignment.

Instructor observation 1. Students were observed posting messages, reminders, and questions as they worked effectively in their group. There was evidence of students' interacting respectfully with their members, making necessary compromises, and assuming shared responsibility in collaborating on the final group poster (see Figures 11 to 13). Suggestions on improving the final product was also observed as an indication that members valued the individual contributions made by other team members

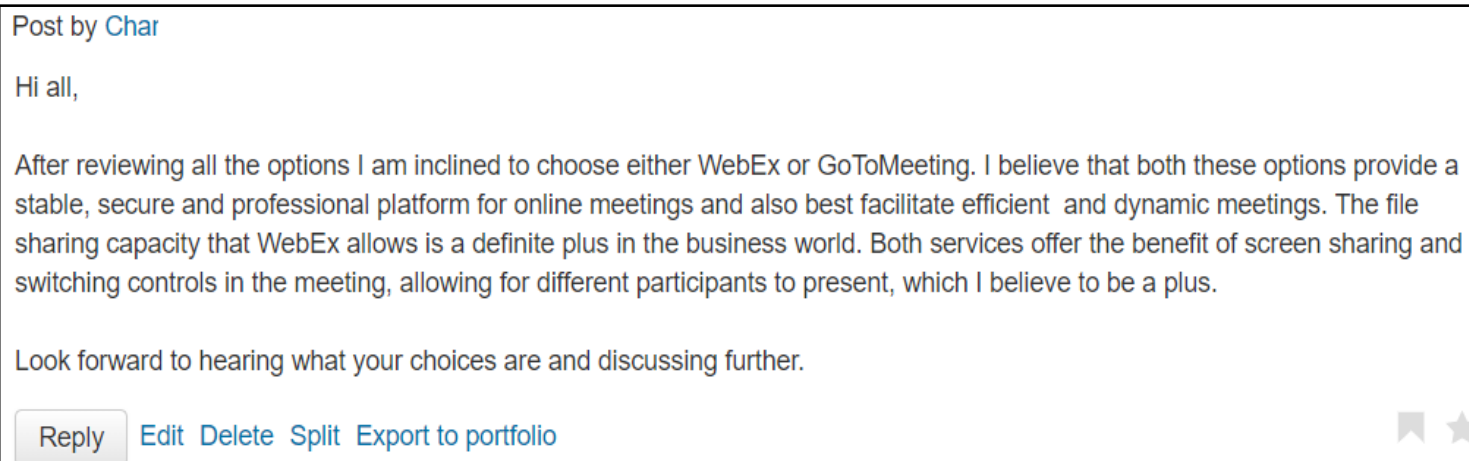

1Figure 11. Student summarizing a series of posts for the group.

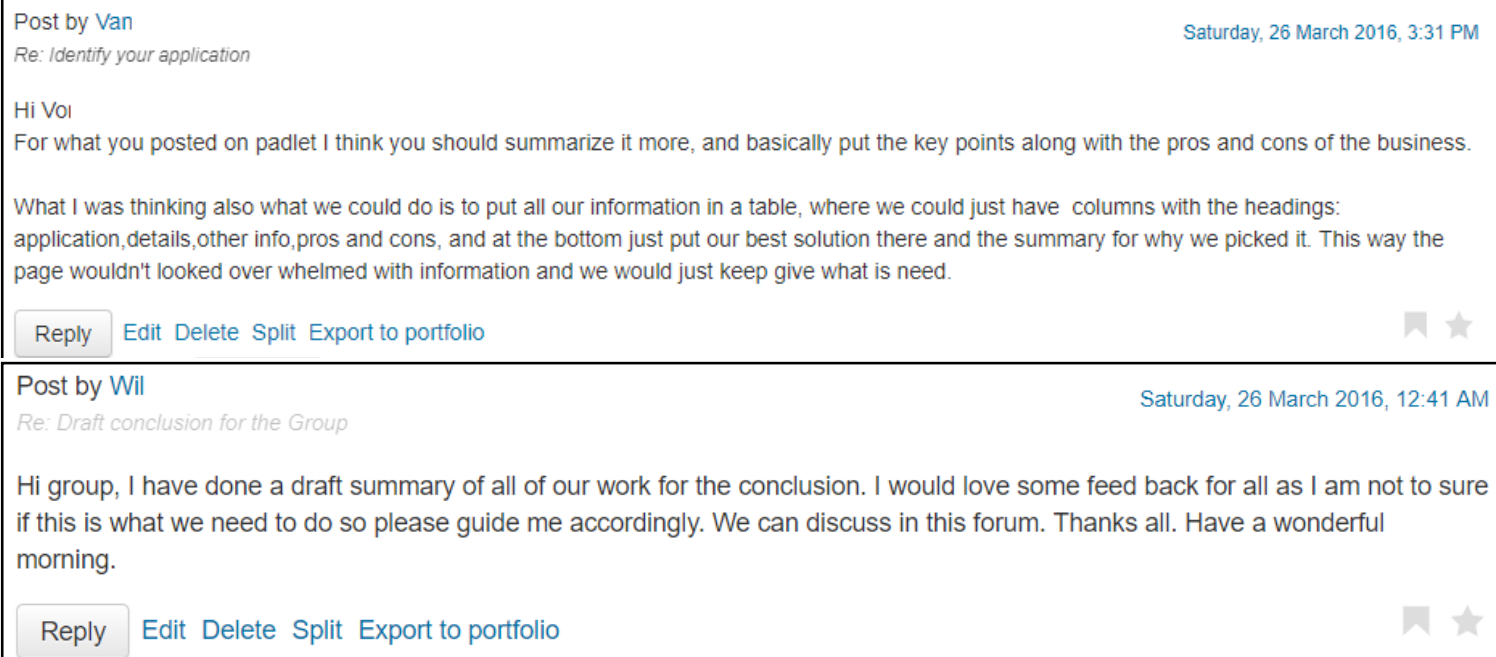

Figure 12. Requesting feedback from other group members. 
From Discussion Forums to eMeetings: Integrating High Touch Strategies to Increase Student Engagement, Academic Performance, and Retention in Large Online Courses

Post by Cory
I like Ex, it seems like the more business video conferencing application because of its nicely designed user interface and
useful file sharing and screen sharing capabilities. Also the ability to record the meetings for anyone who missed it.
Does anyone else think that the padlet is too congested with information? I think it should be a little more spaced out.
Reply Edit Delete Split Export to portfolio

Figure 13. Communicating new ideas to other group members.

Instructor observation 2. Most groups completed their summary poster by the two-week deadline, thus achieving the final objective of the assignment. Samples from the posters shared in Figures 14 and 15 demonstrated creativity and innovation through working together and brainstorming in an online environment.

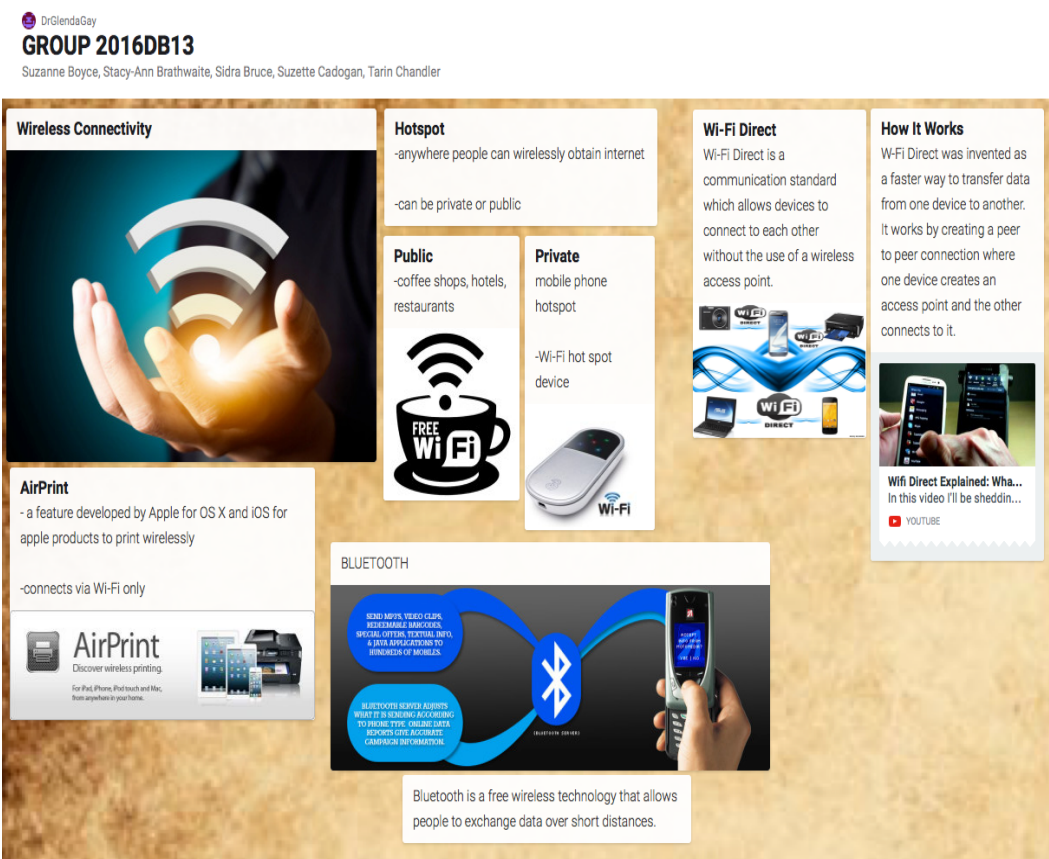

Figure 14. Submission of final online poster by a group-Example A. 


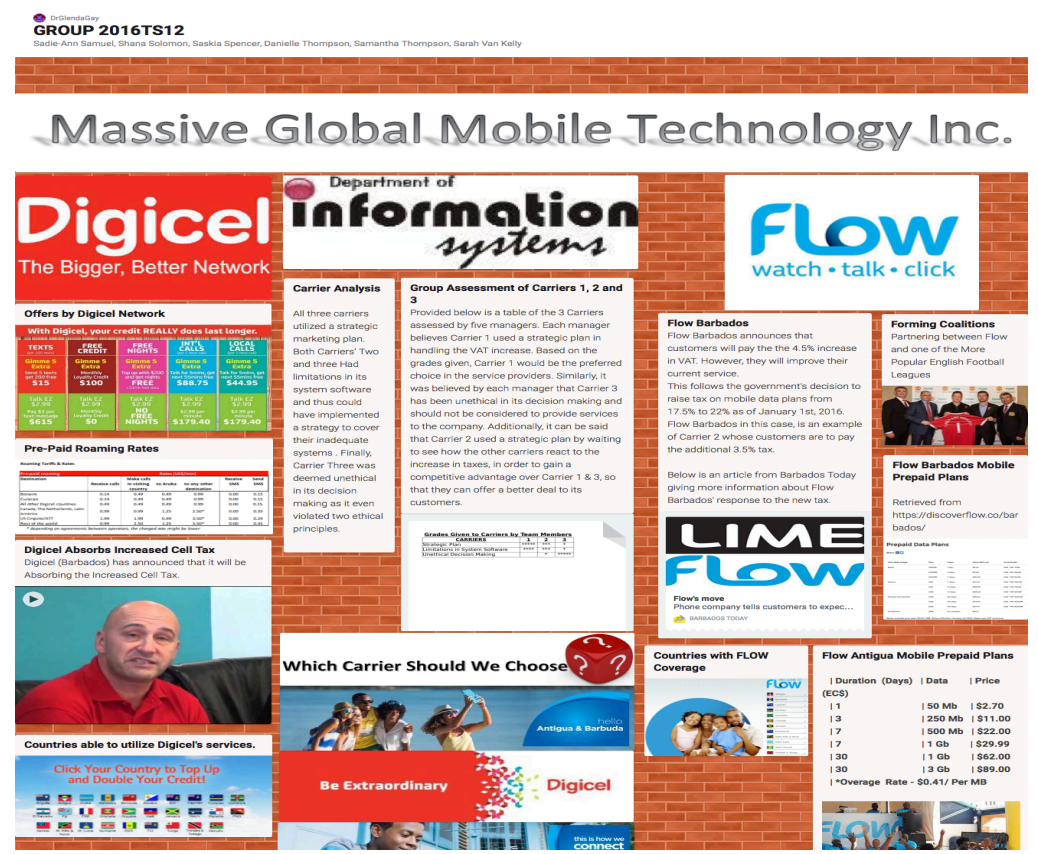

Figure 15. Submission of final online poster by a group-Example B.

\section{Results}

\section{Course Evaluations, and Student Feedback}

Overall data collected showed an increased pass rates, increased student satisfaction, and decrease in student attrition. The following sections provide further details on these results.

Course pass rate. Historically, the overall pass rate for the course ranged between a low of $69 \%$ to a high of $88 \%$ between 2011-2013. While there are fluctuations in these early years, since the integration of the eMeeting with the high touch strategies, the pass rate shows a steady increase with a low of $90 \%$ and a high of $93 \%$ between 2014-2016. Table 4 presents the comparison of overall student pass rates from 2011-2013 and 2014-2016 for each semester.

Table 4

Overall Pass Rates from 2011 to 2016 for Students Who Had Both Coursework and Exam Marks

\begin{tabular}{cccc} 
Year & Semester 1 & Semester 2 & Average \\
\hline 2011 & $69 \%$ & $83 \%$ & $76 \%$ \\
2012 & $79 \%$ & $75 \%$ & $77 \%$ \\
2013 & $86 \%$ & $88 \%$ & $87 \%$ \\
$2014^{\mathrm{c}}$ & $\mathbf{9 1 \%}$ & $\mathbf{9 0 \%}$ & $\mathbf{9 1 \%}$ \\
2015 & $\mathbf{9 1 \%}$ & $\mathbf{9 3 \%}$ & $\mathbf{9 2 \%}$ \\
2016 & $\mathbf{9 3 \%}$ & $\mathbf{9 3 \%}$ & $\mathbf{9 3 \%}$ \\
\hline
\end{tabular}

Note. The UWI refers to the fall and spring semesters respectively as Semester 1, Semester 2. ${ }^{\mathrm{c}}$ indicates the year that the eMeeting design was integrated into the course. 
Course evaluation. The course evaluation is based on a 5-point Likert scale with 1 being Strongly Disagree and 5 being Strongly Agree regarding workload, learning outcomes, and clarity of instructions for completing course work. Data provided from 2014 to 2016 indicated a high level of agreement across three key areas of the evaluation: (a) Lecture's Communication (see Table 5), (b) Learning Activities with the Lecturer (see Table 6), and (c) Feedback from the Lecturer (see Table 7).

Table 5

Instructor's Communication

\begin{tabular}{|c|c|c|c|}
\hline I understood... & 2014 & 2015 & 2016 \\
\hline $\begin{array}{l}\text { the course learning outcomes (learning outcomes = what students } \\
\text { should know/ be able to do by the end of the course) }\end{array}$ & 4.56 & 4.56 & 4.74 \\
\hline $\begin{array}{l}\text { how I could use the knowledge/skills developed during this } \\
\text { course to achieve other goals (e.g. career, further study) }\end{array}$ & 4.71 & 4.64 & 4.79 \\
\hline the instructions for completing assignments/assessments & 4.57 & 4.74 & 4.88 \\
\hline $\begin{array}{l}\text { the criteria that the instructor used to grade my } \\
\text { assignments/coursework }\end{array}$ & 4.61 & 4.77 & 4.83 \\
\hline Overall & 4.61 & 4.68 & 4.81 \\
\hline
\end{tabular}

Table 6

Learning Activities with the Instructor

\begin{tabular}{|c|c|c|c|}
\hline Learning Activities with the Lecturer... & 2014 & 2015 & 2016 \\
\hline were varied (that is, involved different types of activity) & 4.56 & 4.56 & 4.63 \\
\hline were interesting or intellectually stimulating & 4.71 & 4.64 & 4.81 \\
\hline $\begin{array}{l}\text { encouraged me to interact/collaborate with other students about } \\
\text { course topics }\end{array}$ & 4.57 & 4.74 & 4.42 \\
\hline $\begin{array}{l}\text { helped me to develop the knowledge, attitudes and skills } \\
\text { specified in the course learning outcomes (learning outcomes = } \\
\text { what students should know/be able to do by the end of the course) }\end{array}$ & 4.61 & 4.77 & 4.81 \\
\hline $\begin{array}{l}\text { required me to apply my new knowledge and skills to } \\
\text { problems/new scenarios }\end{array}$ & 4.48 & 4.78 & 4.77 \\
\hline Overall & 4.61 & 4.68 & 4.71 \\
\hline
\end{tabular}

Table 7

Feedback from the Instructor

\begin{tabular}{|c|c|c|c|}
\hline Statement & 2014 & 2015 & 2016 \\
\hline $\begin{array}{l}\text { Feedback on assignments/in-course assessments was provided in } \\
\text { sufficient time to be useful }\end{array}$ & 4.56 & 4.56 & 4.83 \\
\hline Feedback helped me to develop/improve my knowledge or skills & 4.71 & 4.64 & 4.78 \\
\hline $\begin{array}{l}\text { Grades for assignments/in-course assessments were based only } \\
\text { on the criteria that the instructor had specified }\end{array}$ & 4.57 & 4.74 & 4.98 \\
\hline Overall & 4.61 & 4.65 & 4.86 \\
\hline
\end{tabular}


Student feedback. As part of course evaluations, students could provide written feedback through open-ended questions. These include additional thoughts or information regarding (a) what they liked best about the course, (b) what they liked least about the course, and (c) how the course could be improved. The last section on lessons learned provided an opportunity for students to share their overall experiences of the course. While most comments were based on experiences with maintaining focus throughout the course or the overall workload, comments from a few students each semester shared the impact of the eMeeting assignment. There were no comments or negative experiences posted specifically regarding with the revamped eMeeting design.

Examples of student feedback from 2014-2016 included:

- The graded group discussion on recycling was effective in its intent to stir up a need to be part of a recycling action, rather than a passive bystander. I feel more confident about what I have to offer in relation to company decision making the impact on the environment (2014).

- In going forward, I would try to implement the knowledge I have gained from the course in my business to enhance its performance (2014).

- I would like to say that from the initial tasks to the project and e-meeting in the board room have all contributed to my learning and the e-meeting definitely had an impact as it provided guidelines as to what I can expect in a meeting, as this was my first "e-meeting experience" (2015).

- This course has thought me a lot about teamwork and I enjoyed every moment of it. For some reason, this course has been the first I have felt so passionate about hence the reason why I felt obligated to participate in every forum in this course (2016).

- I found I was able to directly apply some areas of this course to other courses and in so doing enhanced my understanding of those interconnected areas. I feel ready to apply what I have gleaned to my job and other areas of my life (2016).

Decrease in student attrition. The course has historically had attrition rates of around 5\%. Since the integration of eMeeting design with high touch strategies, the attrition rate dropped to approximately 1\%. Table 8 shows the retention rates from 2011 to 2013 before the new group assignment with high touch strategies was introduced in 2014 to 2016. Table 8 also highlights the overall decrease in student attrition from $5 \%$ to $1 \%$.

Table 8

Summary Data on Number of Students who Dropped the Course Between 2011 and 2016

\begin{tabular}{rcccc}
\hline Year & $\begin{array}{c}\text { Student } \\
\text { enrollment }\end{array}$ & $\begin{array}{c}\text { Number of } \\
\text { students who } \\
\text { completed course }\end{array}$ & $\begin{array}{c}\text { Number of students } \\
\text { who dropped course }\end{array}$ & $\begin{array}{c}\text { Percentage of } \\
\text { students who dropped } \\
\text { course }\end{array}$ \\
\hline 2011 & 801 & 760 & 41 & $5.1 \%$ \\
2012 & 834 & 790 & 44 & $5.3 \%$ \\
2013 & 751 & 715 & 36 & $4.8 \%$ \\
2014 & 547 & 534 & 13 & $2.4 \%$ \\
2015 & 484 & 476 & 8 & $1.7 \%$ \\
2016 & 469 & 464 & 5 & $1.1 \%$ \\
\hline
\end{tabular}

Note. Data was obtained from final exam mark sheets for both course work and final exam marks. 
From Discussion Forums to eMeetings: Integrating High Touch Strategies to Increase Student Engagement, Academic Performance, and Retention in Large Online Courses

\section{Recommendations}

There are five recommendations from this study that align with the OHT conceptual framework. Each recommendation builds upon the literature and makes a connection to the context and results of this action research study. The recommendations can be used in courses whether they range from low to very large enrollments to support engagement and retention.

\section{High Touch Student Engagement Strategy: Enhance Directions with Instructor-Led Videos}

It is recommended that instructors develop supporting materials beyond the syllabus. These materials can include instructor-led videos and useful examples used in this study, which describe the approach and purpose of an assignment to ensure that all requirements are clear. The instructorled videos should reference the assignment document and detailed course work rubric, so that students are aware of how they would be assessed.

\section{High Touch Personalized Communication Strategy: Provide Examples for Self- Introductions}

It is recommended that as part of the requirements, students introduce themselves in preparation for interacting in an activity. Examples could also be shared on how students should introduce themselves in an online environment. Similarities in students' names, if sorted, could be used as an icebreaker during initial introductory posts. Instructors should also be aware that it is important to provide creative and personalized feedback to students whether individually or as a group. Apart from demonstrating that that they are interested in students' contributions, personalized posts can also serve to encourage students who have yet to join or engage in the threads for various reasons.

\section{High Touch Community Development Strategy: Require Collaborative Agreement}

It is recommended that instructors integrate strategies that actively engage students with topics relevant to weekly/module content, current/emerging issues, and prior or upcoming assignments. These assignments in which students collaborate could include tasks that require interaction asynchronously or synchronously.

\section{High Touch Work-Integrated Learning Strategy: Integrate Role Play Using Real-world Contexts}

It is recommended that assignments align with real-world contexts, to support transfer of learning. This offers opportunities for communication, critical thinking, problem solving, and collaboration.

\section{High Touch Data-Driven Decision-Making Strategy: Review Quantitative and Qualitative Data}

A consistent review of quantitative and qualitative data from assessments and evaluations is recommended. Thus, monitoring various aspects of the course can assist in modifying current assignments or integrating new course assignments into courses with large student enrollments.

These five high touch recommendations are provided to instructors as they seek to actively engage students in large classes. The eMeeting-type assignment, as shared in this study, has shown to assist students in developing the knowledge, skills, and experience needed as they transition from the educational classroom to the corporate sector. 


\section{Conclusion}

The UWI is committed to providing all students with the same high-quality courses across all instructional modalities, and alignment with the program outcomes, 21st Century Skills, and The UWI's attributes. This study has demonstrated that an online discussion forum can be successfully designed and introduced to students as an eMeeting or other real-world group activity. The results show that since the integration of the new eMeeting format using OHT strategies, significant increases were observed in student engagement and academic performance, while a comparison between the pre- and post-integration revealed decreases in attrition, and higher scores on the standardized final exam. Course evaluations between 2014-2016 also reflect increased student satisfaction with the course.

The integration of the new eMeeting design using high-touch strategies was successful for students in this assignment. Future research could involve using these strategies in other course assignments requiring group work to further evaluate learning outcomes and capture students' experiences. Monitoring of student attrition obtaining feedback could determine if these types of strategies influence student satisfaction and retention. eMeetings can be used, by students and instructors alike, as a valuable teaching tool especially simulating real-world group meetings. Integrating group assignments in large courses with real-world requirements, not only provide students with the opportunity to apply the knowledge, skills, and experience gained throughout the course, but enhance key soft skills sought by employers including problem-solving, ability to work in teams, communication, leadership, and time management. 
From Discussion Forums to eMeetings: Integrating High Touch Strategies to Increase Student Engagement, Academic Performance, and Retention in Large Online Courses

\section{References}

AACSB International. (2013). Eligibility procedures and accreditation standards for business accreditation (Adopted April 8, 2013). Retrieved from

aacsb.edu/-/media/aacsb/docs/accreditation/business/standards-and-tables/2018-businessstandards

Astin, A. W. (1984). Student involvement: A developmental theory for higher education. Journal of College Student Personnel, 24(4), 297-308.

Bauer-Wolf, J. (2018, February 23). Overconfident students, dubious employers. Inside Higher Ed. Washington, DC. Retrieved from https:/www.insidehighered.com/news/2018/02/23/studystudents-believe-they-are-prepared-workplace-employers-disagree

Berry, R. W. (2009). Meeting the challenges of teaching arge online classes: Shifting to a learnerfocus. MERLOT Journal of Online Learning and Teaching, 5(1). http://jolt.merlot.org/vol5no1/berry_0309.htm

Betts, K. (2008). Online human touch (OHT) instruction and programming: A conceptual framework to increase online student engagement and retention in online education, Part 1. Journal of Online Learning and Teaching, 4(3), 399-418.

Betts, K., Kramer, R., \& Gaines, L. L. (2011). Online faculty and adjuncts: Strategies for meeting current and future demands of online education through online human touch training and support. International Journal of Online Pedagogy and Course Design, 1. 20-38. doi: 10.4018/ijopcd.2011100102

Bitter, C., \& Loney, E. (2015). Deeper learning: Improving student outcomes for college, career, and civic life. American Institutes for Research.

Boton, E. C., \& Gregory, S. (2015). Minimizing attrition in online degree courses. The Journal of Educators Online, 12(1), 62-90.

Briggs, A. (2015, Feb.). Ten ways to overcome barriers to student engagement online. Online Learning Consortium. Retrieved from onlinelearningconsortium.org/news_item/tenwaysovercome-barriers-student-engagement-online/

Buzzetto-More, N. (2015). Student attitudes towards the integration of YouTube in online, hybrid and web-assisted courses: An examination of the impact of course modality on perception. Journal of Online Learning and Teaching , 11(1), 55-73.

Bigatel, P. (2016, March 14). Student engagement strategies for the online learning environment. Faculty Focus. Retrieved from https://www.facultyfocus.com/articles/onlineeducation/student-engagement-how-to-help-students-succeed-in-the-online-environment/

Chickering, A. W., \& Gamson, Z. F. (1987). Seven principles for good practice in undergraduate education. AAHE Bulletin, 39(7), 3-7.

Cohen, L., \& Manion, L. (1994). Research methods in education (4th ed). Routledge.

Cranton, A., \& Legge, L. H. (1978). Program evaluation in higher education. The Journal of Higher Education, 49(5), 464-471.

Csikszentmihalyi, M. (1990). Flow: The psychology of optimal experience. Harper \& Row.

Efron, S. E., \& Ravid, R. (2013). Action research in education: A practical guide. Guilford Press. 
From Discussion Forums to eMeetings: Integrating High Touch Strategies to Increase Student Engagement, Academic Performance, and Retention in Large Online Courses

Elison-Bowers, P., Sand, J., Barlow, M. R., \& Wing, T. J. (2011). Strategies for managing large online classes. The International Journal of Learning, 18(2), 57-66.

Faharani, G. O. (2003). Existence and importance of online interaction (Doctoral dissertation, Virginia Polytechnic Institute, 2003). Retrieved from http://scholar.lib.vt.edu/theses/available/etd-04232003 202143/unrestricted/Gohar-FarahaniDissertation.pdf

Framework for 21 st century learning. (n.d.). Partnership for 21st-century learning Retrieved from http://www.battelleforkids.org/networks/p21/frameworks-resources

Goldie, J. (2016). Connectivism: A knowledge learning theory for the digital age? Medical Teacher, 38(10), 1064-1069. https://doiorg.ezproxy2.library.drexel.edu/10.3109/0142159X.2016.1173661

Kolb, D. A. (2014). Experiential learning: Experience as the source of learning and development. Pearson Education Ltd.

Laux, D., Luse, A., \& Mennecke, B. (2016). Collaboration, connectedness, and community: An examination of the factors influencing student persistence in virtual communities. Computers in Human Behavior, 57, 452-464. doi:10.1016/j.chb.2015.12.046

Lederman, D. (2018, November 7). Online Education Ascends. Inside Higher Ed. Retrieved from https://www.insidehighered.com/digital-learning/article/2018/11/07/new-data-onlineenrollments-grow-and-share-overall-enrollment

Mehrabian, A. (1971). Silent messages. Wadsworth.

Milne, P. (2005). A model for work integrated learning: Optimizing student learning outcomes. World Association for Cooperative Education (WACE). Retrieved January 16, 2018, from http://www.waceinc.org/pdf/A\%20Model\%20for\%20Work\%20Integrated\%20Learning\%20 \%20Optimizing\%20Student\%20Learning\%20Outcomes\%20-\%20Milne.pdf

Mokoena, S. (2013). Engagement with and participation in online discussion forums. The Turkish Online Journal of Educational Technology, 12(2), 97-105.

Norton, L. (2018). Action research in teaching and learning: A practical guide to conducting pedagogical research in universities. Retrieved from https://ebookcentral-proquestcom.ezproxy2.library.drexel.edu

Palloff, R. M., \& Pratt, K. (1999). Building learning communities in cyberspace: Effective strategies for the online classroom. Jossey-Bass Inc.

Parsons, R. D., \& Brown, K. S. (2002). Teacher as reflective practitioner and action researcher. Wadsworth/Thomson Learning.

Reuters. (2017, June 15). Global e-learning market 2017 to boom $\$ 275.10$ billion value by 2022 at a CAGR of 7.5\%. Orbis Research. Reuters Solutions. Retrieved from https://www.reuters.com/brandfeatures/venture-capital/article?id=11353

Rose, K. K. (2009). Student perceptions of the use of instructor-made videos in online and face-toface classes. Journal of Online Learning and Teaching, 5(3), 8. Retrieved from http://jolt.merlot.org/vol5no3/rose_0909.htm

Rose, R., \& Smith, A. (2007). Chapter 9 online discussions. In C. Cavanaugh, \& R. Blomeyer (Eds.), What works in k-12 online learning (pp. 143-160). International Society for Technology in Education. 
From Discussion Forums to eMeetings: Integrating High Touch Strategies to Increase Student Engagement, Academic Performance, and Retention in Large Online Courses

Spencer, J. (2017). Making learning flow. Solution Tree Post.

Stanford-Bowers, D. (2008). Persistence in online classes: A study of perceptions among stakeholders. MERLOT Journal of Online Learning and Teaching, 4, 37-50. Retrieved from http://jolt.merlot.org/vol4no1/stanford-bowers0308.pdf

The University of the West Indies. (2016). The University of the West Indies Strategic Plan 20122017. The University Office of Planning and Development. Retrieved from http://www.uwi.edu/sf-docs/default-source/planningdocs/UWI_Strategic_Plan_20122017_Final.pdf

Thomas, L., Herbert, J., \& Teras, M. (2014). A sense of belonging to enhance participation, success and retention in online programs. The International Journal of the First Year in Higher Education, 5(2), 69-80. doi:10.5204/intjfyhe.v5i2.233

Tinto, V. (1993). Leaving college: Rethinking the causes and cures of student attrition. University of Chicago Press.

Toney, K. (2017, Aug 10). Five ways to keep students engaged in their online classes. Distance and Online Learning. Retrieved from https://evolllution.com/revenuestreams/distance_online_learning/five-ways-to-keep-students-engaged-in-their-onlineclasses/

Trammell, B. A., \& LaForge, C. (2017). Common challenges for instructors in large online courses: Strategies to mitigate student and instructor frustration. Journal of Educators Online, 14(1), $1-10$.

Vik, G. N. (2001). Doing more to teach teamwork than telling students to sink or swim. Business Communication Quarterly, 64, 112-119.

Wilsman, A. (n.d.). Teaching large classes. Vanderbilt University's Center for Teaching. Retrieved December 18, 2018, from https://wp0.vanderbilt.edu/cft/guides-sub-pages/teaching-largeclasses/

Yong, A. (2003). Success factors in e-learning implementation. The Star in Tech, 22(19), 19.

$\mathrm{Yu}, \mathrm{J} .$, \& Hu, Z. (2016). Is online learning the future of education? World Economic Forum. Retrieved August 8, 2017, from https://www.weforum.org/agenda/2016/09/is-onlinelearning-the-future-of-education/ 